\title{
Corrigendum: Low Testosterone in Adolescents \& Young Adults
}

\author{
Jordan Cohen ${ }^{1 *}$, Daniel E. Nassau ${ }^{2}$, Premal Patel ${ }^{1}$ and Ranjith Ramasamy ${ }^{1}$ \\ ${ }^{1}$ Department of Urology, University of Miami Miller School of Medicine, Miami, FL, United States, ${ }^{2}$ Department of Urology, \\ Lenox Hill Hospital, Donald and Barbara Zucker School of Medicine at Hofstra/Northwell, New York, NY, United States
}

Keywords: testosterone, obesity, diabetes, adolescence, fertility

\section{OPEN ACCESS}

Approved by:

Frontiers Editorial Office,

Frontiers Media SA, Switzerland

*Correspondence:

Jordan Cohen

jac617@med.miami.edu

Specialty section:

This article was submitted to

Reproduction,

a section of the journal

Frontiers in Endocrinology

Received: 29 May 2020

Accepted: 08 June 2020

Published: 14 July 2020

Citation:

Cohen J, Nassau DE, Patel P and Ramasamy $R$ (2020) Corrigendum: Low Testosterone in Adolescents \&

Young Adults.

Front. Endocrinol. 11:449.

doi: 10.3389/fendo.2020.00449

\section{A Corrigendum on}

Low Testosterone in Adolescents \& Young Adults

by Cohen, J., Nassau, D. E., Patel, P., and Ramasamy, R. (2020). Front. Endocrinol. 10:916. doi: 10.3389/fendo.2019.00916

In the original article, we neglected to state a commercial relationship. A correction has been made to Conflict of Interest: "RR is an investigator for Aytu Biosciences, the manufacturer of Natesto." The corrected Conflict of Interest statement appears below. The authors apologize for this error and state that this does not change the scientific conclusions of the article in any way. The original article has been updated.

\section{CONFLICT OF INTEREST}

$\mathrm{RR}$ is an investigator for Aytu Biosciences, the manufacturer of Natesto.

The remaining authors declare that the research was conducted in the absence of any commercial or financial relationships that could be construed as a potential conflict of interest.

Copyright $\odot 2020$ Cohen, Nassau, Patel and Ramasamy. This is an open-access article distributed under the terms of the Creative Commons Attribution License (CC BY). The use, distribution or reproduction in other forums is permitted, provided the original author(s) and the copyright owner(s) are credited and that the original publication in this journal is cited, in accordance with accepted academic practice. No use, distribution or reproduction is permitted which does not comply with these terms. 